Paidéia, 2002, 12(23), 93-103

\title{
TEORIAS IMPLÍCITAS DA INTELIGÊNCIA: ESTUDOS NO CONTEXTO ESCOLAR PORTUGUÊS ${ }^{1}$
}

\author{
Luísa Faria \\ Universidade do Porto - Portugal
}

\begin{abstract}
RESUMO: Neste artigo, discutem-se as teorias implícitas ou pessoais da inteligência de alunos e professores portugueses, apresentando um conjunto de estudos de natureza transversal e longitudinal. As concepções pessoais de inteligência dos alunos são discutidas à luz da teoria de Dweck, que salienta o seu caráter estático $v s$. dinâmico. As teorias pessoais dos professores são conceptualizadas segundo a perspectiva das representações sociais e os estudos de Mugny e Carugati. Finalmente, discute-se a dupla função das teorias implícitas, que se reparte entre a construção de um conjunto de explicações plausíveis e coerentes a nivel individual e a construção de uma identidade social e pessoal gratificantes, destacando-se o papel dos contextos sociais de existência na construção e desenvolvimento das teorias pessoais de inteligência.
\end{abstract}

Palavras-chave: inteligência; teorias implícitas; contexto escolar.

\section{IMPLICIT THEORIES OF INTELLIGENCE: STUDIES IN THE PORTUGUESE SCHOOL CONTEXT}

\begin{abstract}
This article aims to discuss implicit or personal theories of intelligence of Portuguese students and teachers, presenting a group of studies of cross-sectional and longitudinal designs. Students' personal conceptions of intelligence are discussed according to Dweck's theory, which emphasizes the static vs. dynamics aspects of intelligence. The teachers' personal theories are conceptualized following the social representations of intelligence framework and Mugny and Carugati's studies. Finally, we discuss the double role of implicit theories, which simultaneously involves the construction of consistent and plausible explanations at an individual level and the construction of gratifying social and personal identities, emphasizing the importance of social contexts in the construction and development of personal theories of intelligence.
\end{abstract}

Key-words: Intelligence; implicit theories; school context

A inteligência é um construto psicológico de grande relevância social, tendo originado inúmeras investigações nos domínios da Psicologia e da Educação: a existência de uma correlação positiva entre o quociente de inteligência (QI) e os resultados escolares é, aliás, uma das constatações mais antigas e mais regularmente confirmadas pela Psicologia (Reuchlin, 1991).

As investigações no domínio da inteligência podem agrupar-se em duas grandes correntes: a das

\footnotetext{
'Artigo recebido para publicação em janeiro de 2002; aceito em março de 2002

${ }^{2}$ Endereço para correspondência: Luísa Faria, Faculdade de Psicologia e de Ciências da Educação, Universidade do Porto, Portugal, Rua do Campo Alegre, 1055, Porto, Portugal, Cep 4169-004, E-mail Ifaria@psi.up.pt
}

teorias explícitas - conjunto de construções teóricas de psicólogos, educadores e outros investigadores, que se fundam numa avaliação da inteligência através de testes, designada como avaliação "objetiva" da inteligência (Faria \& Fontaine, 1993; Sternberg, 1985; Sternberg, Conway, Ketron \& Bernstein, 1981); e a das teorias implícitas - conjunto de construções mentais que qualquer indivíduo, leigo ou investigador, pode produzir acerca da inteligência e que podem ser explicitadas e, até, avaliadas a partir de auto-relatos (Dweck \& Elliott, 1983; Faria \& Fontaine, 1993; Goodnow, 1980; Nicholls, Pastashnick \& Mettetal, 1986; Vandenplas-Holper, 1987).

As teorias implícitas da inteligência, até agora menos investigadas, parecem-nos de grande relevo 


\section{Luísa Faria}

e atualidade, nomeadamente porque permitem compreender as concepções que os indivíduos têm sobre a natureza da inteligência, compará-las com as dos especialistas e observar se são partilhadas por determinados grupos sociais, que se podem definir por terem em comuns contextos profissionais em que a ação sobre a inteligência é um objetivo explícito, como é o caso do contexto escolar, logo de professores e de alunos.

O presente artigo tem como objetivo apresentar uma síntese de um conjunto de estudos, por nós desenvolvidos, no domínio das teorias implícitas de inteligência de alunos e de professores, que foram realizados no contexto educativo português, com amostras de alunos do $5^{\circ}$ ao $11^{\circ}$ anos de escolaridade, que abrangem o $2^{\circ} \mathrm{e} 3^{\circ}$ ciclos do ensino básico e o ensino secundário, e com professores dos mesmos ciclos do ensino oficial português.

Assim, serão apresentados resultados de vários estudos transversais e de um estudo longitudinal sobre as concepções pessoais de inteligência de alunos, evidenciando as suas componentes estática ou dinâmica, que se fundam na perspectiva sociocognitiva de Dweck (1999) e que enfatizam a construção individual da inteligência no contexto escolar (Faria, 1996, 1997, 1998; Faria \& Fontaine, 1997), bem como os resultados de um estudo transversal com uma amostra de professores portugueses, em que são investigadas as representações dos professores sobre a natureza $\mathrm{e}$ o desenvolvimento da inteligência, tendo como referência os estudos realizados por Mugny \& Carugati (1989), com professores suíços e italianos.

Resumindo, pretendemos demonstrar que as teorias implícitas de inteligência apresentam uma dupla função - repartida entre a construção de um conjunto de explicações mentalmente plausíveis e coerentes a nível individual e a construção de uma identidade social e pessoal gratificantes (Faria \& Fontaine, 1993; Mugny \& Carugati, 1985, 1989) -, facilitadora de um melhor desempenho cognitivo e promotora do desenvolvimento e do bem-estar psicológico global dos indivíduos.

\section{Concepções pessoais de inteligência de alunos portugueses}

\section{Definição}

O modelo teórico proposto por Dweck e colaboradores (Bandura \& Dweck, 1985; Cain \&
Dweck, 1989; Dweck, 1999) apresenta as concepções pessoais de inteligência como crenças implícitas e diferenciadas acerca da natureza da capacidade intelectual, à volta das quais se organizam objetivos de realização e padrões de comportamento, cognição e afeto distintos (padrões de realização).

As concepções pessoais de inteligência são teorias implícitas, pois as percepções dos indivíduos acerca da natureza da capacidade intelectual, apesar de poderem não ser claramente manifestas (implícitas), são relativamente sistemáticas e coerentes (teorias), influenciando com regularidade o comportamento e podendo ser alvo de avaliação explícita (Cain \& Dweck, 1989; Faria, 1998). Uma das concepções, denominada estática, envolve a crença de que a inteligência é um traço global e estável, limitado em quantidade e incontrolável. Os sujeitos que adotam esta concepção acreditam que possuem uma quantidade fixa e específica de inteligência, demonstrável através da realização, e que os resultados obtidos a permitem avaliar. A outra concepção, denominada dinâmica, envolve a crença de que a inteligência é um conjunto dinâmico de competências e conhecimentos, susceptível de desenvolvimento através de esforços e investimentos pessoais, portanto controlável. Os sujeitos que adotam esta concepção de inteligência (dinâmica) centram-se mais na promoção do seu desenvolvimento do que na sua demonstração (Dweck \& Bempechat, 1983; Faria, 1990, 1998).

Saliente-se, também, que por volta do fim da escolaridade básica todos os sujeitos conseguem perceber os aspectos fundamentais de ambas as concepçōes, mas tendem a orientar-se preferencialmente por uma delas quando pensam acerca da inteligência (Dweck \& Bempechat, 1983; Dweck \& Elliott, 1983; Elliott \& Dweck, 1988; Faria, 1998). Ora, estas concepções funcionam como construtos organizadores, originando uma integração diferenciada de experiências dos sujeitos nos vários contextos de realização e orientando de forma distinta a sua ação nos mesmos contextos (Fontaine \& Faria, 1989).

De referir, ainda, que os sujeitos com diferentes concepções pessoais de inteligência parecem adaptar, também, objetivos de realização distintos: a concepção estática, ao gerar preocupações com a imagem pessoal de competência e com os aspectos avaliativos da realização (associados a juízos positi- 
vos ou negativos da capacidade), promove a adoção de objetivos centrados no resultado, mais susceptíveis de proteger a imagem pessoal, procurando juízos positivos e evitando juízos negativos; pelo contrário, a concepção dinâmica de inteligência, ao gerar preocupações relacionadas com o domínio da tarefa e o desenvolvimento de competências através do esforço e do investimento, promove a adoção de objetivos centrados na aprendizagem, mais adequados à promoção da competência própria (Faria, 1998).

Estes objetivos de realização, por sua vez, estão na base da adoção de padrões de realização, de acordo com a seguinte relação: os objetivos centrados no resultado promovem a adoção de padrões de desistência - caracterizados pelo evitamento das situações percebidas como difíceis e pela deterioração da realização perante o fracasso - enquanto que os objetivos centrados na aprendizagem promovem a adopção de padrões de persistência - caracteriza- dos pela escolha de tarefas desafiadoras e por elevados níveis de realização e de persistência perante os obstáculos (Diener \& Dweck, 1978, 1980; Dweck \& Leggett, 1988).

Sintetizando e sistematizando, o Quadro 1 apresenta-nos a relação prevista entre as concepções pessoais de inteligência, os objetivos de realização e os padrões de realização e, no plano das conseqüências práticas para os indivíduos, parece-nos de realçar que as concepções dinâmicas acerca da inteligência (crença nas possibilidades de desenvolvimento da inteligência através do esforço e do investimento pessoais), representam respostas que permitem ultrapassar mais facilmente as situações de fracasso, estando relacionadas com interpretações e análises mais construtivas acerca do modo mais eficaz para lidar com dificuldades e obstáculos, podendo ser consideradas mais adaptativas e estimulantes de aprendizagens (Faria, 1996).

Quadro 1: Modelo das relações previstas entre concepções pessoais de inteligência, objetivos de realização e padrões de cognição-afeto-comportamento

\begin{tabular}{|c|c|c|}
\hline $\begin{array}{l}\text { Concepções pessoais } \\
\text { de inteligência }\end{array}$ & $\begin{array}{l}\text { Estática } \\
\text { (Inteligência como quantidade fixa e } \\
\text { estável) }\end{array}$ & $\begin{array}{l}\text { Dinâmica } \\
\text { (Inteligência como conjunto de } \\
\text { competências e conhecimentos que } \\
\text { podem ser desenvolvidos através do } \\
\text { esforço) }\end{array}$ \\
\hline Objetivos de realização & $\begin{array}{l}\text { Centrados no resultado } \\
\text { (avaliar o nivel de capacidade) }\end{array}$ & $\begin{array}{l}\text { Centrados na aprendizagem } \\
\text { (aumentar a capacidade) }\end{array}$ \\
\hline \multicolumn{3}{|c|}{ Padrões de cognição-afeto-comportamento (Padrões de realização) } \\
\hline Definição do sucesso & $\begin{array}{l}\text { Resultado elevado/ Baixo esforço em } \\
\text { comparação corn os outros }\end{array}$ & $\begin{array}{l}\text { Aumento da competência } \\
\text { relativamente à realização passada }\end{array}$ \\
\hline Erros & Sinal de falta de capacidade & $\begin{array}{l}\text { Informação útil para o } \\
\text { desenvolvimento da capacidade }\end{array}$ \\
\hline Padrões de realização & Rigorosos, rígidos & Flexíveis, atingíveis \\
\hline Dispêndio de esforço & Ameaçador & Positivamente valorizado \\
\hline Reações afetivas & Orgulho ou alívio, ansiedade & $\begin{array}{l}\text { Excitação, entusiasmo, } \\
\text { aborrecimento, desapontamento }\end{array}$ \\
\hline Comparação social & Função auto-avaliativa & $\begin{array}{l}\text { Usada para adquirir informaçã̀o } \\
\text { acerca das melhores estratégias para a } \\
\text { solução da tarefa }\end{array}$ \\
\hline Escolha de tarefas & $\begin{array}{l}\text { Que maximizem a demonstração } \\
\text { de capacidade. }\end{array}$ & $\begin{array}{l}\text { Que maximizem as oportunidades de } \\
\text { aprendizagem }\end{array}$ \\
\hline
\end{tabular}

Adaptado de Bandura \& Dweck (1985). 


\section{Estudos das concepcõos pessoais de inteli- gência no contexto escolar português} ligência

Avaliação das concepções pessoais de inte-

A avaliação no domínio das concepções pessoais de inteligência tem sofrido significativos avanços metodológicos, que revelam o interesse desta e nesta perspectiva, e acompanham os seus desenvolvimentos teóricos.

Ora, a necessidade de construir um novo instrumento de avaliação das concepções pessoais de inteligência, para adolescentes portugueses, ficou a dever-se à inexistência de instrumentos adaptados ao contexto português. A opção por construir, em vez de traduzir e adaptar o instrumento já existente, ficou a dever-se quer ao fato deste englobar um reduzido número de itens (três), o que era susceptível de aumentar o peso da variância "erro" nas avaliações efetuadas, quer ao fato de se dirigir primordialmente a pré-adolescentes ( 10 a 12 anos de idade), não permitindo, assim, o estudo do desenvolvimento das concepções pessoais de inteligência durante 0 período da adolescência, que constituía um objetivo de estudo primordial para nós (Faria, 1995, 1998).

A construção desta nova escala passou pelas seguintes fases: em primeiro lugar (i), pela elaboração de um primeiro conjunto de itens baseado quer nos estudos de Dweck e colaboradores sobre as concepções pessoais de inteligência, bem como nas respectivas conseqüências para a adoção e prossecução de objetivos e padrões de realização particulares, quer na perspectiva dos jovens portugueses sobre questões relacionadas com o esforço, a capacidade e as diferentes manifestações de competência, avaliadas através de entrevistas individuais semi-estruturadas (Quadro 2); em segundo lugar (ii), por um estudo de reflexão falada dos itens construídos, junto de um grupo de 24 adolescentes do $5^{\circ}$ ao $11^{\circ}$ anos de escolaridade, de modo a avaliar, numa situação de face a face, o significado e a relevância dos itens para os sujeitos, o que permitiu introduzir mudanças formais em palavras e expressões do questionário, bem como no seu formato; e, em terceiro lugar (iii), por um primeiro estudo das suas qualidades psicométricas, através da administração de uma versão do instrumento, resultante das duas fases anteriores, com 26 itens misturados ( 15 da concepção "estática" e 11 da concepção "dinâmica"), avaliados numa escala de Likert de 6 pontos (de "discordo totalmente" a "concordo totalmente", em que o aspecto "dinâmico", ou "não estático", corresponde à cotação superior), a uma amostra de 222 alunos do $5^{\circ}$ ao $11^{\circ}$ anos de escolaridade, de ambos os sexos e dos níveis sócio-econômicos (NSE) alto e baixo, de diferentes escolas da cidade do Porto.

Quadro 2: Temas desenvolvidos por pelo menos $70 \%$ dos sujeitos no âmbito das entrevistas

- Importância do esforço em contexto escolar

- Relação entre capacidade e esforço

- Caracterização do "bom aluno"

- Distinção entre inteligência e esperteza

- Situações em que se sentiram inteligentes e capazes

- Papel do "erro": forma de aprendizagem vs. sinal de incompetência

- Estratégias adaptadas para evitar a demonstração de incompetência em contexto escolar

- Comparação da realização escolar própria com a dos pares

- Significado das "más notas"

- Desenvolvimento da inteligência: potencialidades e limites

Adaptado de Faria (1990).

A propósito do estudo das qualidades psicométricas do instrumento, é de referir que o mesmo compreendeu o estudo da fidelidade pelo método da consistência interna, através do coeficiente alpha de Cronbach, o da validade fatorial, através da análise fatorial, com rotação varimax, e o da sensibilidade ou poder discriminativo dos itens. Assim, os resultados evidenciaram que o valor do coeficiente alpha para a escala total foi de $0 ; 78$, revelandose o coeficiente alpha da escala "estática" superior $(0,82)$ ao da escala "dinâmica" $(0,76)$; por sua vez, a análise fatorial revelou a existência de dois fatores distintos, um "dinâmico" e o outro "estático"; e, finalmente, o poder discriminativo dos itens "estáticos" mostrou-se superior ao dos itens "dinâmicos".

Esta nova escala, construída no e para o contexto português, resultou da interação sistemática entre os pressupostos da teoria e os fatos da prática, 
sendo de salientar que a avaliação das suas qualidades psicométricas evidenciou a sua fidelidade e a sua sensibilidade na avaliação das concepções pessoais de inteligência em jovens alunos a freqüentar a escola do $5^{\circ}$ ao $11^{\circ}$ ano, bem como a sua validade fatorial, que revelou as suas potencialidades para a elaboração de um quadro conceptual explicativo do desenvolvimento diferencial das concepções pessoais de inteligência durante a adolescência (Faria, 1995).

Estudos transversais em função do ano de esćolaridade, do sexo e do nível sócio-econômico (NSE)

Os resultados de três estudos transversais, realizados no contexto educativo português, demonstram uma evolução das concepções pessoais de inteligência, em função do ano de escolaridade, no sentido de concepções progressivamente mais dinâmicas ao longo dos vários anos de escolaridade (desde o $5^{\circ}$ ano - 11 anos de idade -, até ao $11^{\circ}$ ano - 17 anos de idade): de fato, os sujeitos de anos de escolaridade superiores $\left(9^{\circ}\right.$ e $11^{\circ}$ anos) apresentam-se menos estáticos (mais dinâmicos) do que os de anos de escolaridade inferiores $\left(5^{\circ}\right.$ e $7^{\circ}$ anos).

No entanto, a ausência de outros resultados empíricos, nomeadamente do contexto norte-americano, relativos à evolução das concepções pessoais de inteligência com o ano de escolaridade, levounos a explorar vários cenários possíveis para explicar estes resultados no contexto português. Concretizando, o desenvolvimento das concepções pessoais de inteligência, ao longo da escolaridade, deverá ser estudado numa investigação longitudinal, a partir de duas hipóteses alternativas: (i) o desenvolvimento de concepções pessoais de inteligência progressivamente mais dinâmicas é devido ao efeito uniformizante da escola, que conduz à adesão progressiva e sistemática a estas representações mais dinâmicas; ou, (ii) a seleção dos sujeitos com concepções pessoais de inteligência mais dinâmicas é devida ao efeito de uniformização da escola, que opera em termos de abandono seletivo dos alunos com concepções mais estáticas. Neste quadro, é ainda de prever que estas duas hipóteses alternativas possam, ou não, agir simultaneamente (Faria, 1990, 1996, 1998).
Os estudos relacionados com a diferenciação das concepções pessoais de inteligência, em função do sexo, têm apontado para o fato das raparigas adaptarem concepções mais estáticas de inteligência e evidenciarem padrões de realização de desistência (Leggett, 1985; Licht \& Dweck, 1984; Licht, Linden, Brown \& Sexton, 1984): ora, os nossos estudos transversais, já referidos, não evidenciaram quaisquer diferenças significativas entre rapazes $\mathrm{e}$ raparigas nas concepções pessoais de inteligência (Faria, 1990, 1998; Faria \& Fontaine, 1989).

Então, podemos afirmar que, provavelmente, certas características específicas do contexto sócio-cultural português podem ter alterado o tipo de diferenciação esperado (Faria, 1996). De fato, mudanças recentes no contexto português - em particular a partir de Abril de 1974 -, nomeadamente nos valores políticos, econômicos e sociais, bem como nos estereótipos ligados ao sexo, poderão explicar a ausência de diferenças: a estas mudanças poderá estar associada a entrada massiva da mulher portuguesa no mercado de trabalho e em todos os níveis de ensino, nomeadamente na Universidade, sugerindo, assim, que o investimento no sucesso acadẹmico e profissional, por parte das mulheres, é desejável e cada vez mais compatível com os papéis sociais atribuídos à mulher na cultura portuguesa (Faria, 1998).

Os resultados de estudos em função do NSE (alto, médio e baixo) evidenciaram a existência de diferenças significativas nas concepções pessoais de inteligência entre os sujeitos de NSE baixo e os de NSE alto e médio: os de NSE baixo apresentaram concepções significativamente mais "estáticas" do que os de NSE alto e médio (Faria, 1990, 1996, 1998). Para explicar estes resultados, sem comprovação empírica noutros contextos sócio-culturais, nomeadamente no contexto norte-americano, foram avançadas algumas hipóteses exploratórias, que se fundam na análise de experiências vividas pelos sujeitos do grupo de NSE baixo: entre estas, a falta de oportunidades de ascensão social pode conduzir os sujeitos a adaptar concepções estáticas de atributos pessoais, nomeadamente de capacidade intelectual, através de mecanismos de aprendizagem social. De fato, a ausência de contingência entre as tentativas para alterar aspectos negativos da realização ou desempenho individual e os resultados alcançados, pode 
conduzir os sujeitos a atribuir os resultados negativos à falta de capacidade pessoal (Faria, 1990, 1996, 1998; Seligman, 1992).

\section{Estudo longitudinal-seqüencial}

O estudo longitudinal por nós preconizado, sob a égide das duas hipóteses alternativas já referidas, concretizou-se como estudo longitudinalsequiencial, tendo sido realizado com dois anos de intervalo e com uma amostra de 1529 alunos, do $5^{\circ}$ ao $11^{\circ}$ anos de escolaridade, tendo revelado a ausência de qualquer tipo de evolução das concepções pessoais de inteligência com o tempo, bem como a inexistência de qualquer influência significativa de fatores de diferenciação inter-individuais como o ano de escolaridade, o sexo e o NSE na constância intraindividual (Faria, 1996, 1998).

Com o objetivo de clarificar as razões para a ausência de qualquer tipo de evolução intra-individual, foram realizadas análises das diferenças nas concepções pessoais de inteligência entre os alunos "perdidos" da primeira para a segunda fase do estudo e os alunos que permaneceram nele. Tais análises justificam-se na medida em que ocorreu, entre a primeira e a segunda fase do estudo longitudinal, um fenômeno de perda seletiva de sujeitos, com maior incidência nos sujeitos de NSE baixo. Estas análises permitiram concluir que ocorreu uma perda seletiva de sujeitos com concepções mais estáticas de inteligência. Deste modo, foi confirmada a hipótese da generalização de concepções progressivamente mais dinâmicas de inteligência devido ao efeito uniformizante da escola, que opera em termos da seleção dos alunos com concepções mais dinâmicas e provoca o abandono seletivo dos alunos com concepções mais estáticas. De fato, perderam-se os alunos que potencialmente poderiam evoluir mais, ficando os que provavelmente não sofreriam grandes alterações evolutivas nas concepções pessoais de inteligência, o que justifica a ausência de diferenças intra-individuais entre as duas fases do estudo longitudinal-seqüencial.

Assim, a escola parece não ter proporcionado experiências susceptíveis de promover as concepções pessoais de inteligência dos sujeitos, num sentido mais dinâmico, limitando-se, por um lado, a privilegiar e a exigir este tipo de concepção e, por outro lado, a penalizar os sujeitos com concepções estáticas, mais orientados para os resultados e para a comparação social, logo mais preocupados em obter avaliações favoráveis de competência e evitar juízos negativos da mesma (Faria, 1996, 1998).

Contrariamente às previsões, fundadas nos resultados diferenciais de estudos com design transversal, em função do ano de escolaridade, do sexo e do NSE, os resultados do estudo longitudinalseqüencial evidenciaram uma certa estabilidade das concepções pessoais de inteligência com o tempo, nos diversos contextos de existência. Uma análise detalhada dos sujeitos "perdidos", no decurso do estudo longitudinal, evidenciou o fato destes se apresentarem mais estáticos: este resultado parece ilustrar o papel normalizador da escola que, enquanto local de aprendizagem de normas sociais, pode determinar critérios de avaliação da inteligência e da normalidade e, conseqüentemente, recompensar ou punir os comportamentos, em função da sua maior ou menor adaptação às exigências imediatas (Faria, 1998).

$\mathrm{Na}$ verdade, os resultados obtidos apoiam a necessidade de introduzir a intervenção psicológica deliberada no contexto escolar, nomeadamente no sentido da promoção de concepções pessoais de inteligência mais adaptativas, pois a escola, por si só, não parece poder constituir-se espontaneamente como contexto facilitador dessa promoção e desenvolvimento (Faria, 1996, 1998).

Então, sendo a escola "uma instituição cuja função explícita é a promoção do desenvolvimento da capacidade intelectual, veiculando através das suas práticas e atividades, concepções acerca da definição, origem e natureza da inteligência" (Faria \& Fontaine, 1993, p. 472), podemos conjecturar que as definições e avaliações da inteligência dos alunos estão diretamente ligadas a um conjunto muito importante de intervenientes na escola, os professores, cujas representações da inteligência influenciam os seus comportamentos e o seu exercício profissional. Portanto, considerando a relevância da função do professor no domínio da inteligência, particularmente no que se refere às suas teorias implícitas ou representações acerca da inteligência, desenvolvemos um estudo com professores no contexto português, cujos resultados passamos a apresentar. 
Representações dos professores portugueses acerca da natureza e do desenvolvimento da inteligência

\section{Enquadramento}

Os professores, no seu trabalho quotidiano, realizam avaliações da inteligência e confrontam-se com as diferenças de realização intelectual entre os alunos, que têm que explicar e fundamentar. As situações complexas com que os professores se confrontam, envolvendo múltiplos fatores e a tomada de decisões rápidas, exigem que estes possuam esquemas mentais que facilitem a ação, entre eles as representações acerca da inteligência (Faria \& Fontaine, 1993).

Os estudos de Mugny e Carugati (1985, 1989), com pais e professores nos contextos suíço e italiano, demonstram como a posição social do sujeito pode influenciar a sua concepção de inteligência, nomeadamente porque os professores partilhavam a teoria do dom natural na explicação acerca da natureza da inteligência, colocando a responsabilidade pelo fracasso dos alunos fora do seu âmbito de controlo (explicação de origem genética), como forma de proteger e manter a sua identidade social positiva intacta (Faria \& Fontaine, 1993).

Por sua vez, estudos realizados por Snellman e Räty (1992), no contexto finlandês, chegaram a conclusões semelhantes com amostras de pais e professores finlandeses.

Assim, considerando a influência das representações dos professores acerca da inteligência nas suas relações com os alunos e nas suas estratégias didáticas explícitas (Parsons, Graham \& Honess, 1983; Snellman \& Räty, 1992), foi realizado um estudo com 209 professores portugueses, com o objetivo de conhecer as suas representações acerca da natureza e desenvolvimento da inteligência.

\section{Avaliação das representações da inteligên-}

cia

A avaliação das representações dos professores portugueses, acerca da natureza e desenvolvimento da inteligência, foi realizada através de um questionário adaptado ao contexto português por Faria e Fontaine (1993), a partir do questionário construído por Mugny e Carugati $(1985,1989)$.
Esta adaptação, permitiu concretizar um questionário de avaliação com duas partes distintas: a primeira, centrada nas representações da natureza da inteligência, com 66 itens; a segunda, incidindo nas representações do desenvolvimento da inteligência, com 57 itens. Em ambas as partes é pedido aos professores que avaliem as afirmações propostas, numa escala de tipo Likert de 6 pontos, entre "concordo totalmente" (6) e "discordo totalmente" (1).

Finalmente, os dados recolhidos foram tratados por análises fatoriais, tal como nos estudos de Mugny e Carugati, para evidenciar a estrutura das representações dos professores, e para permitir uma comparação mais fácil dos resultados obtidos.

Estudo das representações da inteligência de professores portugueses

Neste estudo, a análise dos resultados obtidos, junto de uma amostra de 209 professores dos $5^{\circ}, 7^{\circ}, 9^{\circ}$ e $11^{\circ}$ anos de escolaridade, evidenciou que o "relativismo na definiçăo de inteligência" (existem múltiplas definições relacionadas com diferenças inter e intra-culturais), foi considerado o fator primordial pelos professores portugueses (Quadro 3), contrariamente ao que aconteceu com as amostras de Mugny e Carugati, cujos resultados salientaram a "teoria do dom natural" (herança genética). "Contudo, tanto num caso como noutro, a responsabilidade pelas diferenças intelectuais não cabe aos professores, mas a uma instância social ou natural superior, crença esta que tem um efeito desculpabilizante e protetor da identidade profissional dos docentes" (Faria \& Fontaine, 1993, p. 482).

Quadro 3: Representações dos professores portugueses acerca da natureza da inteligência: Fator 1 "Relativismo na Definição de Inteligência" 


\section{F1 - Relativismo na Definição de Inteligência ou Definição Sócio-Crítica}

(12,5\% da Variância Total)

1. Se algumas categorias sociais parecem mais inteligentes é porque são elas próprias que definem o que é a inteligência e impõem aos outros essa definição

2. Os membros das culturas que se qualificam de "primitivas" são inteligentes à sua maneira

3. Os ricos inventaram a noção de inteligência para justificar a sua riqueza e o seu poder

4. Se os homens passam por ser mais inteligentes do que as mulheres, é porque são eles que definem o que é a inteligência

5. Cada cultura propõe a sua definição do que é a inteligência

6. Os testes de inteligência são enganadores: não medem mais do que as diferenças, principalmente econômicas, que existem entre diferentes categorias sociais

7. Só pode haver uma definição do que deve ser a inteligência

Adaptado de Faria e Fontaine (1993).

De referir, ainda, que nesta investigação se observou a aceitação pelos professores portugueses de uma definição de inteligência como adaptação e conformismo às regras sociais, em geral, e às regras escolares, em particular (Quadro 4). A aceitação de tal definição, pela amostra de professores portugueses, pode evidenciar uma certa defesa dos privilégios da escola, enquanto instituição capaz de determinar critérios de avaliação da inteligência: deste modo, o papel do professor não pode deixar de passar pela transmissão das regras da instituição escolar e pelo reforço de comportamentos considerados mais adaptados a este contexto (Faria \& Fontaine, 1993).

Quadro 4: Representações dos professores portugueses acerca da natureza da inteligência: Fator 2 "Conformismo / Adaptação Social"

\section{F2 - Inteligềncia Social ou Conformismo / Adaptação Social \\ (7,4\% da Variância Total)}

1. A inteligência define a adaptação do indivíduo ao seu ambiente físico

2. A inteligência é a capacidade do indivíduo para se adaptar à sociedade onde vive

3.Ser inteligente é saber apresentar-se da melhor maneira

4.A inteligência é a capacidade da criança para

compreender o sentido que o professor dá a uma questāo

Adaptado de Faria e Fontaine (1993).
Os professores também manifestaram a crença de que o desenvolvimento da inteligência exige um bom ambiente afetivo na escola, mas os efeitos deste são limitados pela influência da família, que os professores interpretam como sendo uma influência "biologizante" ou "natural" (Quadro 5).

Quadro 5: Representações dos professores portugueses acerca do desenvolvimento da inteligência: $\mathrm{Fa}$ tor 3 "Inteligência como Herança Familiar"

\section{F3 - Inteligência como Herança Familiar/Sis- tema de Valores Familiares (5,8\% da Variância Total)}

1. "Tal pai, tal filho": isto é verdadeiro mesmo para a inteligência

2. As crianças inteligentes são oriundas de famílias em que os pais valorizam a inteligência

Adaptado de Faria e Fontaine (1993).

Em síntese, a complexidade e as contradições envolvidas nas representações da inteligência, dos professores portugueses, espelham as complexidades e as contradições inerentes à situação educativa no contexto escolar, compreendendo, simultaneamente, a necessidade de construir um universo de explicações, que sendo plausíveis do ponto de vista pessoal, sejam também coerentes com uma identidade social e pessoal gratificantes, identidade esta que exige aos professores que acreditem na sua função de promoção do desenvolvimento e da aprendizagem (Faria \& Fontaine, 1993; Mugny \& Carugati, $1985,1989)$.

\section{Conclusão}

\section{Papel da escola na promoção de teorias pessoais de inteligência mais adaptativas $e$ desenvolvimentais}

A importância das teorias pessoais de inteligência resulta do fato das ações dos indivíduos, em contextos de realização, não dependerem apenas da sua capacidade intelectual objetiva, pois também agem movidos pelas concepções pessoais acerca da natureza da sua capacidade intelectual, bem como pelas percepções que têm acerca das relações entre a capacidade e o esforço, na explicação dos resultados 
da realização. Deste modo, o conhecimento das teorias pessoais, ou implícitas, dos indivíduos pode ser utilizado para prever as avaliações que estes fazem de si próprios e dos outros (Faria \& Fontaine, 1993). No entanto, é também de referir que a interpretação pessoal diferenciada da inteligência, demonstrada por alunọs com distintas experiências de socialização, nos vários contextos de vida, reforça a necessidade de adaptar uma outra perspectiva, que substitua o estudo de traços estáveis pelo estudo dos processos motivacionais, bem como o ponto de vista individual pelo de interação do sujeito com o contexto social (Faria, 1998).

De fato, a posição social do sujeito pode influenciar a concepção que ele tem da inteligência. A título de exemplo, saliente-se o caso dos professores, em que a noção de inteligência emerge como representação social heterogênea e conflituante ( $\mathrm{Fa}$ ria \& Fontaine, 1993; Mugny \& Carugati, 1985, 1989).

Portanto, parece importante promover nos alunos concepções de inteligência mais dinâmicas, pois estas permitem conceber o desenvolvimento do esforço de forma paralela e complementar ao desenvolvimento da capacidade e, ao enfatizar o papel ativo do sujeito neste processo, permitem conciliar o investimento nos resultados da realização com o desenvolvimento da capacidade intelectual através da aprendizagem e do esforço (Faria, 1998).

Ora, o papel do professor e das suas teorias pessoais de inteligência assume aqui particular relevo, pois um professor com concepções mais dinâmicas de inteligência necessitará menos de utilizar estratégias de defesa da sua imagem profissional e de encontrar explicações externas para o insucesșo dos alunos, aprendendo com esta situação e esforçandose mais para a resolver. Ou seja, como as teorias pessoais de inteligência dos professores afetam a sua ação no quotidiano escolar, as concepções mais dinâmicas promoverão estratégias e práticas de interação com os alunos, as quais são mais susceptíveis de promover o desenvolvimento das suas capacidades intelectuais através do esforço e do investimento.

Deste modo, considerando este quadro global, podemos sugerir algumas propostas genéricas de intervenção psicológica que, desde as primeiras experiências de confronto com a aprendizagem e a realização no contexto escolar, tenham como objetivos:

(i) Promover uma análise diversificada das explicações dos resultados da realização, sucessos ou fracassos;

(ii) Facilitar a análise do reconhecimento da contingência entre os comportamentos de realização e os resultados, de modo a aumentar as percepções de controlo sobre a realização e a facilitar a ação, promovendo, assim, o sentimento de competência própria;

(iii) Promover a complementaridade de causas como o esforço, a capacidade e o conhecimento na produção e na explicação dos resultados em contexto escolar (o esforço potencia a capacidade e facilita as aprendizagens e o conhecimento);

(iv) Promover estratégias de ensino orientadas para a mestria, pois nestas o sujeito recebe informações importantes acerca dos progressos da sua realização, facilitando a centração no processo e a valorização do esforço;

(v) Promover o desenvolvimento de capacidades que sejam facilitadoras da integração dos aspectos de ambas as concepções, estática e dinâmica, isto é, realçar e coordenar o reconhecimento da existência de diferenças nas várias capacidades dos sujeitos, enfatizando o desenvolvimento e o progresso das mesmas (Faria, 1997);

(vi) Sensibilizar os professores, desde a sua formação inicial, para a importância das teorias pessoais de inteligência dos alunos e dos próprios professores, bem como para o modo como afetam a ação dos indivíduos e o seu relacionamento com os outros.

Saliente-se, contudo, que estas estratégias de intervenção não podem ser perspectivadas como independentes do contexto social em que ocorrem, pois as mudanças ao nível individual só serão produtivas se tiverem correspondência ao nível social (Weiner, 1990).

A inteligência, interpretada socialmente como um recurso humano valioso, não representa apenas uma causa explicativa dos resultados escolares (ou outros), mas também faz parte de valores so- 
ciais mais amplos que influenciam e sustentam a estrutura social, sendo importante conhecer os aspectos morais e éticos que lhe estão subjacentes, pois estes têm implicações nas possibilidades de mudança individual e têm conseqüências no contexto social em que o sujeito se move.

Em suma, o desenvolvimento da capacidade intelectual tambem requer a incorporação das normas e dos valores sociais que determinam os critérios de sucesso ou de fracasso, bem como a distribuição de reforços ou de punições, não podendo, portanto, ser concebido independentemente dos vàlores sociais e dos objetivos da cultura, em geral, e da escola, em particular.

Concluindo, a importância das teorias implícitas da inteligência funda-se e reparte-se entre a dupla função de construir um conjunto de explicações plausíveis e coerentes a nível individual, a par da construção de uma identidade social e pessoal gratificantes.

\section{Referências Bibliográficas}

Bandura, M. \& Dweck, C.S. (1985).Self-conceptions and motivation: Conceptions of intelligence, choice of achievement goals, and patterns of cognition, affect and behavior. Unpublished manuscript. Harvard University: Laboratory of Human Development.

Cain, K.M. \& Dweck, C.S. (1989). The development of children's conceptions of intelligence: A theoretical framework. In R. J. Sternberg (Ed.), Advances in the psychology of human intelligence (pp. 47-82). Hillsdale: Lawrence Erlbaum Associates, Publishers.

Diener, C.I. \& Dweck, C.S. (1978). An analysis of learned helplessness: Continuous changes in performance, strategy and achievement cognitions following failure. Journal of Personality and Social Psychology, 36, 451-462.

Diener, C.I. \& Dweck, C.S. (1980). An analysis of learned helplessness: (II) The processing of success. Journal of Personality and Social Psychology, 39, 940-952.

Dweck, C.S. (1999). Self-theories: Their role in motivation, personality, and development. Philadelphia: Psychology Press.

Dweck, C.S. \& Bempechat, J. (1983). Children's theories of intelligence. In S. Paris, G. Olson \& H. Stevenson (Eds.), Learning and motivation in the classroom (pp. 239-256). Hillsdale: Lawrence Erlbaum Associates, Publishers.

Dweck, C.S. \& Elliott, E.S. (1983). Achievement motivation. In P.H. Mussen (Gen. Ed.) \& E. M. Hetherington (Vol. Ed.), Handbook of child psychology: Vol. IV Social and personality development (pp. 643-691). New York: Wiley.

Dweck, C.S. \& Leggett, E.L. (1988). A socialcognitive approach to motivation and personality. Psychological Review, 95, 256-273.

Elliott, E.S. \& Dweck, C.S. (1988). Goals: An approach to motivation and achievement.Joumal of Personality and Social Psychology, 54, 5-12.

Faria, L. (1990). Concepções pessoais de inteligência. Dissertação de provas de aptidão pedagógica e capacidade científica. Porto: Faculdade de Psicologia e de Ciências da Educação da Universidade do Porto.

Faria, L. (1995). Concepções pessoais de inteligência: Estudos de validação de uma escala para os adolescentes portugueses. Psychologica, 13, 8193.

Faria, L. (1996). Desenvolvimento intra-individual das concepçõ்es pessoais de inteligência durante a adolescência. Revista Portuguesa de Pedagogia, $X X X(1), 17-33$.

Faria, L. (1997). Processos de desenvolvimento diferencial das concepções pessoais de inteligência. Psychologica, 17, 75-83.

Faria, L. (1998). Desenvolvimento diferencial das concepções pessoais de inteligência durante a adolescência. Lisboa: Fundação Calouste Gulbenkian \& Junta Nacional de Investigação Científica e Tecnológica.

Faria, L. \& Fontaine, A.M. (1989). Concepções pessoais de inteligência: Elaboração de uma escala e estudos exploratốrios. Cadernos de Consulta Psicológica, 5, 19-30. 
Faria, L. \& Fontaine, A.M. (1993). Representaçōes dos professores sobre a natureza e desenvolvimento da inteligência. Revista Portuguesa de Pedagogia, XXVII(3), 471-487.

Faria, L. \& Fontaine, A.M. (1997). Adolescents' personal conceptions of intelligence: The development of a new scale and some exploratory evidence. European Journal of Psychology of Education, XII(1), 51-62.

Fontaine, A.M. \& Faria, L. (1989). Teorias pessoais do sucesso. Cadernos de Consulta Psicológica, 5, 5-18.

Goodnow, J J. (1980). Everyday concept of intelligence and its development. In N. Warren (Ed.), Studies in cross-cultured psychology. Vol. 1 (pp. 191-219). New York: Academic Press.

Leggett, E.L. (1985). Children's entity and incremental theories of intelligence: Relationships to achievement behavior. Paper presented at the annual meeting of the Eastern Psychological Association, Boston.

Licht, B.G. \& Dweck, C.S. (1984). Determinants of academic achievement: The interaction of children's achievement orientations with skill area. Developmental Psychology, 20, 628-638.

Licht, B.G., Linden, T.A., Brown, D.A. \& Sexton, M.A. (1984). Sex differences in achievement orientation: An " $A$ " student phenomenon? Paper presented at the meeting of the American Psychological Association, Toronto, Canada.

Mugny, G. \& Carugati, F. (1985). L'intelligence au pluriel. Les représentations socialès de l'intelligence et de son développement. Causset: Éditions Delval.

Mugny, G. \& Carugati, F. (1989). Social representations of intelligence. Cambridge: Cambridge University Press.

Nicholls, J., Patashnick, M. \& Mettetal, G. (1986). Conceptions of ability and intelligence. Child Development, 57, 636-645.

Parsons, J.M., Graham, N. \& Honess, T. (1983). A teacher's implicit model of how children learn. British Educational Research Journal, 9, 91-101.
Reuchlin, M. (1991). Les différences individuelles à l'école. Paris: PUF.

Seligman, M.E.P.(1992). Helplessness. On development, depression and death. New York: W.H. Freeman \& Company.

Snellman, L. \& Räty, H. (1991). Intelligence at school. Social psychological analysis of a multifaced concept. Nordisk Pedagogic, 12, 89-95.

Sternberg, R. (1985). Implicit theories of intelligence, creativity and wisdom. Journal of Personality and Social Psychology, 49(3), 607-627.

Sternberg, R., Conway, B., Ketron, J. \& Bernstein, M. (1981). People's conceptions of intelligence. Journal of Personality and Social Psychology, 4I(1), 17-39.

Vandenplas-Holper, C. (1987). Les théories implicites du développement et de l'éducation. European Journal of Psychology of Education, II(1), 1739.

Weiner, B. (1990). History of motivation research in education. Journal of Educational Psychology, $82,612-622$. 
